\title{
Determinants of stunting and severe stunting among Burundian children aged 6-23 months: evidence from a national cross-sectional household survey, 2014
}

\author{
Sandra Nkurunziza ${ }^{1,2^{*}}$, Bruno Meessen ${ }^{3}$, Jean-Pierre Van geertruyden ${ }^{1}$ and Catherine Korachais ${ }^{3}$
}

\begin{abstract}
Background: Burundi is one of the poorest countries and is among the four countries with the highest prevalence of stunting (58\%) among children aged less than 5 years. This situation undermines the economic growth of the country as undernutrition is strongly associated with less schooling and reduced economic productivity. Identifying the determinants of stunting and severe stunting may help policy-makers to direct the limited Burundian resources to the most vulnerable segments of the population, and thus make it more cost effective. This study aimed to identify predictors of stunting and severe stunting among children aged less than two years in Burundi.
\end{abstract}

Methods: The sample is made up of 6199 children aged 6 to 23 months with complete anthropometric measurements from the baseline survey of an impact evaluation study of the Performance-Based financing (PBF) scheme applied to nutrition services in Burundi from 2015 to 2017. Binary and multivariable logistic regression analyses were used to examine stunting and severe stunting against a set of child, parental and household variables such as child's age or breastfeeding pattern, mother's age or knowledge of malnutrition, household size or socio-economic status.

Results: The prevalence of stunting and severe stunting were 53\% [95\%Cl: 51.8-54.3] and 20.9\% [95\%Cl: 19.9-22.0] respectively. Compared to children from 6-11 months, children of 12-17 months and 18-23 months had a higher risk of stunting (AdjOR:2.1; 95\% Cl: 1.8-2.4 and 3.2; 95\% Cl: 2.8-3.7). Other predictors for stunting were small babies (AdjOR=1.5; 95\% Cl: 1.3-1.7 for medium-size babies at birth and AdjOR=2.9; 95\% Cl: 2.4-3.6 for small-size babies at birth) and male children (AdjOR=1.5, 95\% Cl: 1.4-1.8). In addition, having no education for mothers (AdjOR=1.6; 95\% Cl: 1.2-2.1), incorrect mothers' child nutrition status assessment (AdjOR=3.3; 95\% Cl: 2.8-4), delivering at home (AdjOR=1.4; $95 \% \mathrm{Cl}: 1.2-1.6)$ were found to be predictors for stunting. More than to 2 under five children in the household (AdjOR=1.45; 95\% Cl: 1.1-1.9 for stunting and AdjOR=1.5; 95\% Cl: 1.2-1.9 for severe stunting) and wealth were found to be predictors for both stunting and severe stunting. The factors associated with stunting were found to be applicable for severe stunting as well.

(Continued on next page)

\footnotetext{
* Correspondence: nkurunzizasandra@gmail.com

${ }^{1}$ Global Health Institute, University of Antwerp, Gouverneur

Kinsbergencentrum, Doornstraat 331-, -2610 Wilrijk, BE, Belgium

${ }^{2}$ Health Community Department, University of Burundi, Boulevard du 28

NovembreBP 1020 Bujumbura, Burundi

Full list of author information is available at the end of the article
} 
(Continued from previous page)

Conclusion: Mother's education level, mother's knowledge about child nutrition status assessment and health facility delivery were predictors of child stunting. Our study confirms that stunting and severe stunting is in Burundi, as elsewhere, a multi-sectorial problem. Some determinants relate to the general development of Burundi: education of girls, poverty, and food security; will be addressed by a large array of actions. Some others relate to the health sector and its performance - we think in particular of the number of children under five in the household (birth spacing), the relationship with the health center and the knowledge of the mother on malnutrition. Our findings confirm that the Ministry of Health and its partners should strive for better performing and holistic nutrition services: they can contribute to better nutrition outcomes.

Keywords: Stunting, undernutrition, children, Burundi

\section{Background}

One of the sustainable development goals (SDGs) is to end all forms of malnutrition by 2030 [1]. There are two categories of malnutrition: on the one hand undernutrition which encompasses stunting, wasting and deficiencies of micronutrients (i.e. vitamins and minerals) and on the other hand overweight, obesity due to over-consumption of specific nutrients. Worldwide, in 2014, 23.8\% of the children under-five years of age were stunted following the WHO definition, $7.5 \%$ were wasted but $6.1 \%$ had overweight or were obese $[2,3]$.

Undernutrition makes children more vulnerable to severe diseases. In 2015, undernutrition was considered to be an underlying contributing factor in about $45 \%$ of the 5.9 million children who died under the age of five. Actually, the number of global deaths and DALYs lost among children under-five years of age attributed to maternal and child undernutrition constitutes the largest percentage of all risks in this age group]. Moreover, child undernutrition is a strong predictor for less schooling and reduced economic productivity when adult $[4,5]$, which in turn are both risk factors for raising undernourished children, making it all a vicious circle. Thus, the fight against malnutrition is a long term investment for health but also for economic growth and social wellbeing for both present and future generations.

Developing countries host the bulk of the global stunting and child mortality rate. The situation is particularly critical in Sub-Sahara Africa where one third of the stunted under-five years of age children are retrieved and where stunted children are 14 times more likely to die before the age of five[6]. Actually, although the global trend in stunting has been decreasing from $39.6 \%$ in 1990 to $23.8 \%$ in 2014 , the absolute number of stunted children in Africa has increased by $23 \%$ within the same period $[3,7]$. This dramatic situation calls for actions; African leaders have to set up strategic plans to reduce both the epidemiologic and socioeconomic burden of malnutrition, and turn the vicious circle into a virtuous one.

There is a large body of evidence on the factors of malnutrition in Low Income Countries (LICs) and sub-Saharan
Africa. A multi-national cohort study revealed an association between poverty and stunting [8]. Suboptimal breastfeeding, and inappropriate complementary feeding practices, recurrent infections and micronutrient deficiencies are also important determinants of stunting $[9,10]$. When poverty becomes an permanent condition, it leads to a cumulative inadequate food intake and poor health conditions from which arises stunting [11]: the increased frequency and severity of infections in poorly nourished children results in growth impairment[11]. More comprehensively, linear growth failure occurs within a complex interplay of other more distant community and societal factors, such as access to healthcare and education, political stability, urbanization, population density and social support networks: this has been described in the World Health Organization (WHO) Conceptual Framework on Childhood Stunting [12] (Figure 1).

This research zooms in on malnutrition in Burundi, one of the poorest countries in the world with an estimated per capita gross national income of \$280 in 2013 [13]. Densely populated, it has a population of approximately 10.6 million inhabitants on a total area of 27,830 square kilometers and $90 \%$ of the population is living in rural areas from agriculture and $61.5 \%$ of the population in this area cannot meet their basic needs in terms of calorie intake [13]. Burundi has the highest prevalence of stunting (58\%) worldwide, together with Timor Leste [14]. Burundian children aged less than five years suffer from an important mortality rate of $82 \%$ per year [15].

The available literature on the Burundian nutrition context consists mainly in reports from different partners in health looking at the trend of acute and chronic malnutrition in the most affected provinces of the country [16]. Beside those descriptive reports, there is an impact evaluation report of a nutrition program run in two provinces of eastern Burundi between 2010 and 2014. The two-year impact of the nutrition program consisting of three core components (distribution of food rations, participation in behavior change communication sessions delivered via care groups and attendance at preventive health services) had been positive on household 


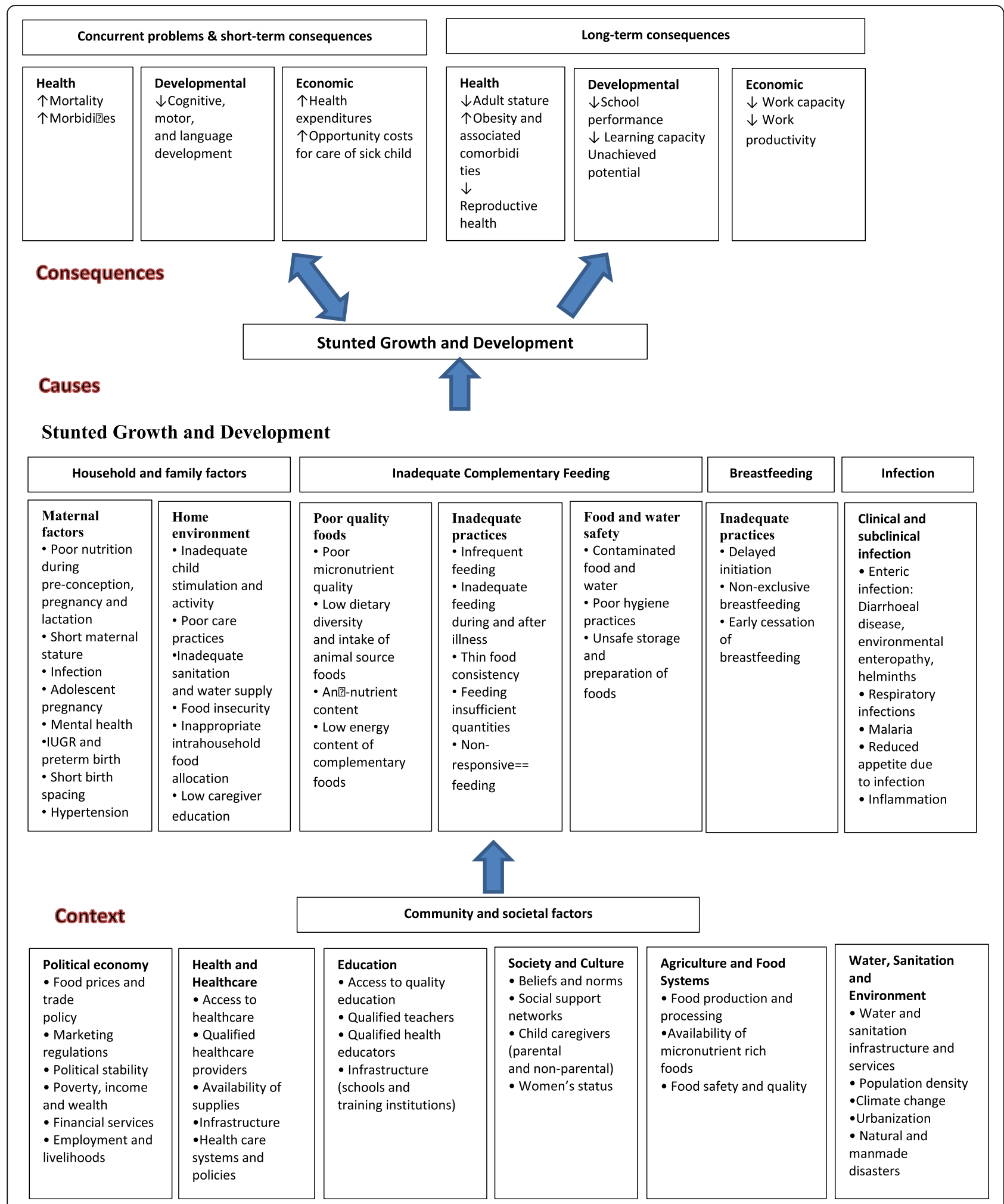

Fig. 1 WHO conceptual framework on Childhood Stunting: Context, Causes, and Consequences 
access to food, child feeding practices and child morbidity. However, as the evaluation came too early in the study process, the impact on child undernutrition could not yet be evaluated [17-19]. A relevant report, in regards to our research, comes from UNICEF who used the 2010 Demographic and Health Survey data (DHS) to assess the predictors factors of child undernutrition in Burundi [20] and found that gender, age, mother's age, wealth index, dependency ratio and region of residence were associated to stunting. Another study explored the impact of the civil war on child's health status found, after controlling for province of residence, birth cohort, individual and household characteristics, and provincespecific time trends, that children exposed to the war have on average 0.52 standard deviations lower heightfor-age z-scores than non-exposed children [21].

We update and complete these findings to have a comprehensive knowledge about the determinants of stunting in the local Burundian context. This is vital to develop prevention strategies and strengthen nutrition intervention programs. We've included more independent variables such as mother's knowledge, household's food security, breastfeeding, birth weight proxy, place of delivery, arable land ownership. The findings should help policy-makers to direct the limited Burundian resources to the most vulnerable segments of the population, and thus make it more cost effective. It may also help in designing new intervention strategies aimed at reducing the number of malnourished children. Therefore, the aim of the study was to identify predictors of stunting and severe stunting among children aged less than two years in Burundi.

\section{Methods}

\section{Study design and sample size}

We used household baseline data from an impact evaluation study which aims to measure and understand the effects of the Performance-Based Financing (PBF) scheme applied to nutrition services in Burundi at facility level and community level. The protocol of this impact evaluation is described elsewhere [22]. Briefly, the study has a cluster-randomized controlled trial design, with health center as the primary unit of sampling and sous-colline (the smallest administrative entity with a variable number of villages) as the secondary unit sampling. The sample size was computed on the smallest difference in the main outcome that can be considered of public health significance which is equivalent to a reduction of $\cong 25 \%$ in acute malnutrition prevalence $(2.5 \%$ points in absolute terms) in intervention centers as compared to control centers. Assuming that the intervention will decrease the prevalence of moderate acute malnutrition in children aged 6 to 23 months from 10\% to 7.5\% [23] while accepting a 2 -sided $\alpha$-error of $5 \%$ and a $\beta$-error of $20 \%$ indicated to survey at least 65 children aged 6-23 months in the catchment area of each health center. Among the 193 health centers providing nutritional services, 90 health centers were randomly selected (computer-based randomization) and randomized to either the intervention or control group. The number of children per health center was increased to 72 to allow for missing or incomplete data, amounting to a total of 6,480 children aged 6-23 months. The Nutrition PBF impact evaluation study is registered on ClinicalTrials.gov with the following identifier: NCT02721160 [22].

\section{Data Collection}

Households were eligible for the survey when (i) they had at least one child aged 6-23 months and (ii) the eligible child was present together with their mother or primary caregiver and the household head. The first visited household was chosen as follows: from the center of the sous-colline, a pen was thrown in the air to indicate the direction to be taken by the surveyors; following this direction, the first household reached with an eligible child was the first to be surveyed (only if caregiver and head were present and gave their consent). The surveyors would then continue on the same direction to find the second household to be surveyed, and so on. In case of more than one eligible child in the household, one of them was randomly selected. Data collection tools consisted in three modules: a questionnaire administered to the household head, a questionnaire to the mother and one anthropometrics module. The household head questionnaire allowed to get information on general household characteristics such as household head education, gender and occupation, household size, distance to health center, as well as to assess the household socio-economic status and their food security status. The questionnaire administered to the mother collected information on her age, education, occupation and parity. It also allowed to get information on her feeding practices with the selected child and on her knowledge on nutrition; we also collected information on the health of the child (vaccination status, health problems in the last two weeks, visits to the health center). The module on anthropometrics collected the weight, height, mid-upper arm circumference and presence of edema of the child (as well as the mid-upper arm circumference (MUAC) of the mother).

In the field, surveyors worked in pairs with one supervisor per six pairs of surveyors. Each pair carried a SECA ${ }^{\circ}$ 876 flat scale, a UNICEF measuring board and a SECA ${ }^{\circ}$ 212 measuring tape. Surveyors were given comprehensive training in the taking of anthropometric measurements and a standardization exercise was carried out during the course of the training. The questionnaire was filled in on a smartphone, using the Open Data Kit Collect application[24], which allowed for: adding constraints into the 
data field, automatically skipping irrelevant questions/ filtering to relevant questions, and obliging the surveyor to respond to every question before finalizing the questionnaire. Close supervision also allowed for a good quality control. Finally, lot quality assurance sampling (LQAS) was performed in order to ensure high quality anthropometrics measurements ${ }^{1}$.

\section{Data analysis \\ Stunting}

We used the 2006 World Health Organization (WHO) Child Growth Standards. Height-for-age z-scores were used to assess the chronic nutritional status of children [25]. The height-for-age z-score expresses a child's height in terms of the number of standard deviations (SDs) above or below the median height of healthy children in the same age group or in a reference group. Children with a measurement of $<-2$ SD from the median were considered as short for their age (stunted), while children with measurement of $<-3 \mathrm{SD}$ from the median group were considered to be severely stunted.

\section{Explanatory variables}

The explanatory variables were chosen on the basis of the WHO conceptual framework on childhood stunting [12] which is built on the UNICEF framework on causes of malnutrition (Figure 1). Both frameworks highlight the context, causes and consequences of stunting. However, the basic and underlying causes are more itemized in the WHO conceptual framework enabling a more context specific guidance in developing of nutrition-sensitive strategies.

We classified the factors into three levels: parental-, child-, household-level factors. Parental-level factors include maternal education, mother's age, marital status as well as a variable assessing her knowledge of malnutrition. For the latter, we compared the mother's satisfaction about the child's nutrition status to the actual child's nutrition status and categorized mothers with either a correct or an incorrect assessment of their child's nutrition status.

Child-level factors were age, sex, place of delivery, child's breastfeeding pattern, sickness episode within the two last weeks, feeding practices and a proxy of their birth weight. The age of children was estimated first by using the birth dates reported on their immunization card ( $94 \%$ of children) and only secondary by asking the mother.

In our survey sample, the birth weight was only present on the immunization card in $30 \%$ of the cases. It has been proven from 3 Demographic and Health Surveys (DHS) conducted in three low- and middle-income countries (LMICs) that the mother's perception of size is a good proxy of birth weight [26] and in our study the 30\% children of whom we knew the birth weight was also correlated $(r=-0.44)$ with the mother's perception. Therefore, we used the perceived size of the child at birth by the mother as a proxy of the child's birth weight. Using the twenty-four hours recall on the child's diet and based on the WHO guidelines on indicators assessing infant and young child feeding practices, we compute the minimum acceptable diet which encompasses the minimum dietary diversity and the minimum meal frequency [27].

Household level factors were household head education, food insecurity, socio-economic status, source of drinking water, time to the health center, household size and number of children aged less than 5 years in the household, arable land ownership. The assessment of household food insecurity was based on the 2007 Household Food Insecurity Access Scale (HFIAS) generic questions, created by the Food and Nutrition Technical Assistance (FANTA) project [28]. These have been validated in a number of different contexts and over different timeperiods. The section includes nine occurrence questions, with an increasing level of severity of food insecurity (access) and nine questions concerning 'frequency-ofoccurrence' to determine how often food insecurity occurred [28]. A household wealth index was calculated as a score of household assets such as ownership of means of transport, ownership of durable goods and household facilities. Weights for each variable were obtained thanks to a principal components analysis method [29]. This index was divided into five quintiles, and each household was assigned to one of these categories: poorest, poorer, middle, rich and richest.

\section{Statistical analyses}

To determine the level of stunting and severe stunting in children aged 6-23 months, the dependent variable was expressed as a dichotomous, that is, "not stunted" $(\geq-2 \mathrm{SD})$ or "not severely stunted" ( $\geq-3 \mathrm{SD})$ versus "stunted" (<-2 SD) or "severely stunted" (<-3 SD). Logistic regression analyses were performed using Stata (version 12.1 College Station, Texas 77845 USA). Bivariate analysis was done for all explanatory variables to identify those associated with children stunting and severe stunting. Variables with p-value below 0.10 in the bivariate analysis were included in the multivariable analysis model. Adjustments for the cluster sampling design effects were incorporated using the "vce" command. A manual procedure of stepwise backward elimination process was then used to identify factors that were significantly associated with the study outcomes using $5 \%$ significance level. The adjusted odds ratios (AdjOR) with 95\% confidence Intervals (CIs) were calculated and those with $p<0.05$ were considered to be significant. Collinearity and interaction between independent variables were assessed. 


\section{Results}

\section{Characteristics of the sample}

The respondent rate was $95.7 \%(n=6199)$. The prevalence of stunting and severe stunting were 53.0\% (95\% CI:51.8-54.3) and 21\% (95\% CI:19.9-22.0) respectively (Table 1). Male and female children were nearly equally represented as well as age categories. Among the children who experienced a sickness episode during the two last week 59.1\% (95\% CI:57.9-60.3), the majority had fever 54.6\% (95\% CI:53.0-56.7). 83.9\% (95\% CI:83.0-84.8) of the children were born at a health facility. Almost all children have been breastfed (99.9\%; 95\% CI:99.8-99.9) and $83.4 \%$ (95\% CI:81.7-85.1) of the children aged between 18 and 23 months were still on breastfeeding at the moment of the survey. Only $24.8 \%$ (95\% CI:23.926.0) of the children had the recommended diet

Table 1 Characteristics of children aged 6-23 months: national cross-sectional survey, Burundi 2014

\begin{tabular}{|c|c|c|c|c|c|c|}
\hline Child characteristics & Number & Stunted & Not stunted & Severely stunted & Not severely stunted & $\%[95 \% \mathrm{Cl}]$ \\
\hline Nutrition status & 6199 & & & & & \\
\hline Stunting & & 3291 & 2908 & NA & NA & $53.0 \%[51.8-54.3]$ \\
\hline Severe stunting & & NA & NA & 1301 & 4898 & 20.9\% [19.9-22.0] \\
\hline Sex & 6199 & & & & & \\
\hline Male & & 1747 & 1281 & 778 & 2250 & $48.8 \%[47.6-50.0]$ \\
\hline Female & & 1544 & 1627 & 523 & 2648 & $51.1 \%$ [49.9-52.4] \\
\hline Age (months) & 6199 & & & & & \\
\hline $6-11$ & & 843 & 1338 & 267 & 1914 & $35.1 \%[34.0-36.3]$ \\
\hline $12-17$ & & 1167 & 909 & 447 & 1609 & $33.4 \%$ [32.3-34.6] \\
\hline $18-23$ & & 1281 & 661 & 567 & 1375 & $31.3 \%[30.1-32.4]$ \\
\hline Sickness episode within 2 weeks & 6199 & & & & & \\
\hline No & & 1324 & 1207 & 485 & 2046 & $40.8 \%$ [39.6-42.0] \\
\hline Yes & 3668 & 1967 & 1701 & 816 & 2852 & $59.1 \%[57.9-60.3]$ \\
\hline Diarrhea & & 727 & 556 & 315 & 968 & $34.9 \%$ [33.4-36.5] \\
\hline Fever & & 1086 & 919 & 472 & 1533 & $54.6 \%[53.0-56.7]$ \\
\hline Respiratory infection & & 617 & 600 & 264 & 953 & $33.1 \%[31.6-34.7]$ \\
\hline \multicolumn{7}{|l|}{ Breastfeeding practices } \\
\hline Has been breastfed & 6197 & 3285 & 2906 & 1297 & 4895 & $99,9 \%$ [99.8-99.9] \\
\hline Children weaned & 6164 & 288 & 151 & 134 & 305 & $7.1 \%[6.4-7.7]$ \\
\hline Exclusive 6 months breastfeeding & 6074 & 2654 & 2308 & 1026 & 3936 & $81.6 \%[80.7-82.6]$ \\
\hline \multicolumn{7}{|l|}{ Continuous to be breastfed } \\
\hline 6-11 months & 2176 & 839 & 1331 & 264 & 1906 & $99.7 \%$ [99.5-99.9] \\
\hline 12-17 months & 2067 & 1097 & 855 & 438 & 1514 & $94.44 \%[93.4-95.4]$ \\
\hline 18-23 months & 1921 & 1046 & 557 & 453 & 1150 & $83.4 \%[81.7-85.1]$ \\
\hline \multicolumn{7}{|l|}{ Minimum acceptable diet } \\
\hline All & 6144 & 834 & 701 & 316 & 1219 & $24.8 \%$ [23.9-26.0] \\
\hline 6-11months & 2173 & 161 & 223 & 52 & 332 & $17.6 \%$ [16.0-19.2] \\
\hline 12-17 months & 2060 & 310 & 258 & 120 & 448 & $27.5 \%[25.6-29.0]$ \\
\hline 18-23 months & 1911 & 363 & 220 & 144 & 439 & $30.5 \%$ [28.4-32.5] \\
\hline Place of delivery & 6189 & & & & & \\
\hline Home & & 600 & 395 & 247 & 748 & $16.0 \%$ [15.1-16.9] \\
\hline Health facility & & 2683 & 2511 & 1050 & 4144 & 83.9\% [83.0-84.8] \\
\hline $\begin{array}{l}\text { Birth weight proxy (Mother's perception } \\
\text { on size of the baby at birth) }\end{array}$ & 6174 & & & & & \\
\hline Large & & 579 & 767 & 191 & 1155 & $21.8 \%$ [20.7-22.8\%] \\
\hline Average & & 2157 & 1869 & 833 & 3193 & $65.2 \%$ [64.0-66.4] \\
\hline Small & & 539 & 263 & 267 & 535 & $12.9 \%$ [12.1-13.8] \\
\hline
\end{tabular}


according to their age with respect to frequency and diversity (Table 1 ).

Half of the mothers were aged between 25 and 34 years. Around three quarters of them were without any education and two third had the impression that their babies were of average size at birth. The majority of the households visited were in couple (legally married or not) (91.9\%; 95\% CI:91.3-92.6).

At the moment of the interview, 58.5\% (CI 95\%:57.259.7) of the mothers perceived their children with a correct nutrition status (Table 2). Even though 90.3\% (95\% CI:89.6-91.1) of the households visited had arable land, 91.9\% (95\% CI:91.1-92.5) of them were experiencing food insecurity. The average household's size was five persons (IQR=4-7). Half of the households $(49.8 \%$; $95 \%$ CI:48.5-51.0) lived at more than one hour walking to the health center (Table 3 ).

\section{Factors associated with stunting and severe stunting Child level variables}

Male was found to be associated with stunting ( $\mathrm{cOR}=1.4$; 95\% CI: $[1.3-1.5] ; p<0.001)$ and severe stunting $(\mathrm{COR}=1.7$; 95\% CI: [1.5-1.9]; $p<0.001)$. The odds of being stunted for children aged 12 to 17 months and 18-23 months were respectively two times more (95\% CI: [1.8-2.3] for stunted and $95 \% \mathrm{CI}:[1.7-2.4]$ for severely stunted) and three times more (95\% CI:2.7-3.4 for stunted and 95\% CI:2.5-3.4 for severely stunted) than the odds of children aged 6-11 months (both $p<0.001$ ). Children aged 18-23 months for whom the minimum acceptable diet was correct in the 24 previous hours were less likely to be stunted (cOR=0.78; 95\% CI: 0.64-0.96; $p=0.02)$ and severely stunted (cOR=0.72; 95\% CI: 0.58-0.91; $p=0.005)$ than those from same age category with not appropriate complementary food. Children born at home were more likely to be stunted (cOR=1.4; 95\% CI: 1.2-1.6; $p<0.001)$ and severely stunted (cOR=1.3; 95\% CI: $1.1-1.5 ; p=0.001)$ than those born at health facility.

\section{Parental level variables}

Children whose mothers had no education were more likely to be stunted ( $\mathrm{cOR}=2.3$; 95\% CI: $1.7-3 ; p<0.001$ ) and severely stunted $(\mathrm{cOR}=2.0 ; 95 \%$ CI: 1.3-2.9; $p<0.001)$ than those whose mothers reached secondary school and above. Children who were perceived by their mothers to be of medium or smaller size at birth were more likely to be stunted (cOR=1.5; 95\% CI:1.3-1.7; $p<0.001) \quad(\mathrm{cOR}=2.7 ; 95 \% \mathrm{CI}: 2.2-3.2 ; p<0.001)$ and severely stunted $(\mathrm{cOR}=1.5 ; \quad 95 \% \quad \mathrm{CI}: 1.3-1.8 ; \quad p<0.001)$ (cOR=3.0; 95\% CI:2.4-3.7; $p<0.001)$ than those who were perceived to be larger. Children whose mother was not able to assess correctly the nutrition status were more likely to be stunted (cOR=3.4; 95\% CI: 3.1-3.8; $p<0.001$ ) and severely stunted $(\mathrm{cOR}=1.2 ; 95 \% \mathrm{CI}$ : 1.1-1.14; $p<0.001)$ than those whose mother do know. Beside these common parental level factors associated with stunting and severe stunting in Burundian setting, the marital status of the mother (living in couple) was found to be associated with severe stunting (in couple: cOR:1.5; 95\% CI: 1.2-1.8; $p=0.001$ ).

\section{Household level variables}

Children from a non-educated household head were more likely to be stunted (cOR=1.9; 95\% CI: $1.4-2.4 ; p<0.001)$ and severely stunted (cOR=2.1; 95\% CI: $1.4-3.0 ; p<0.001)$ than children from household head with secondary school

Table 2 Characteristics of the parents: national cross-sectional survey, Burundi 2014

\begin{tabular}{|c|c|c|c|c|c|c|}
\hline Parental Characteristics & Number & $\begin{array}{l}\text { Stunted } \\
\text { children }\end{array}$ & $\begin{array}{l}\text { Not stunted } \\
\text { Children }\end{array}$ & $\begin{array}{l}\text { Severely stunted } \\
\text { children }\end{array}$ & $\begin{array}{l}\text { Not severely } \\
\text { stunted children }\end{array}$ & $\%[95 \mathrm{Cl}]$ \\
\hline Mother's education & 6199 & & & & & \\
\hline No education & & 2449 & 2076 & 990 & 3535 & $73 \%$ [71.8-74.1] \\
\hline Primary & & 765 & 684 & 283 & 1166 & $23.3 \%[22.3-24.4]$ \\
\hline Secondary and above & & 77 & 148 & 28 & 197 & $3.6 \%[3.1-4.1]$ \\
\hline Mother's age & 6081 & & & & & \\
\hline 15-24 years & & 996 & 915 & 385 & 1526 & $31.4 \%[30.2-32.5]$ \\
\hline 25-34 years & & 1564 & 1427 & 620 & 2371 & $49.1 \%[47.9-50.4]$ \\
\hline 34-49 years & & 660 & 519 & 266 & 913 & $19.3 \%$ [18.3-20.3] \\
\hline $\begin{array}{l}\text { Mother's child nutrition assessment } \\
\text { vs current child's nutrition status }\end{array}$ & 6173 & & & & & \\
\hline Uncorrect & & 1799 & 764 & 593 & 1970 & $41.5 \%[4.29-42.7]$ \\
\hline Correct & & 1478 & 2132 & 701 & 2909 & 58. $4 \%$ [57.2-59.7] \\
\hline Marital status & 6199 & & & & & \\
\hline In couple (legally married or not) & & 3012 & 2690 & 1165 & 4537 & $91.9 \%[91.3-92.6]$ \\
\hline Live alone (div/sep/widow) & & 279 & 218 & 136 & 361 & $8.0 \%[7.3-8.6]$ \\
\hline
\end{tabular}


Table 3 Households' characteristics: national cross-sectional survey, Burundi 2014

\begin{tabular}{|c|c|c|c|c|c|c|}
\hline Household Characteristics & $n$ & $\begin{array}{l}\text { Stunted } \\
\text { children }\end{array}$ & $\begin{array}{l}\text { Not stunted } \\
\text { children }\end{array}$ & $\begin{array}{l}\text { Severely stunted } \\
\text { children }\end{array}$ & $\begin{array}{l}\text { Not severely } \\
\text { stunted children }\end{array}$ & $\%[95 \mathrm{Cl}]$ \\
\hline Household Size & 6199 & & & & & \\
\hline$<5$ & & 1752 & 1499 & 689 & 2562 & $52.4 \%[46.3-48.8]$ \\
\hline$\geq 5$ & & 1539 & 1409 & 612 & 2336 & $47.5 \%[46.3-53.6]$ \\
\hline \#Children Under 5 & 6199 & & & & & \\
\hline$\leq 2$ & & 3103 & 2770 & 1127 & 4656 & $94.7 \%[94.1-95.3]$ \\
\hline$>2$ & & 188 & 138 & 84 & 242 & $5.2 \%[4.7-5.8]$ \\
\hline Household head education & 6015 & & & & & \\
\hline No education & & 2206 & 1843 & 916 & 3133 & $67.3 \%[66.1-68.5]$ \\
\hline Primary & & 888 & 818 & 322 & 1384 & $28.3 \%[27.2-29.5]$ \\
\hline Secondary & & 102 & 158 & 32 & 228 & $4.3 \%[3.8-4.8]$ \\
\hline Arable land ownership & 6195 & & & & & \\
\hline No & & 317 & 280 & 134 & 463 & $9.6 \%[8.9-10.3]$ \\
\hline Yes & & 2972 & 2626 & 1166 & 4432 & $90.3 \%$ [89.6-91.1] \\
\hline Source of drinking water & 6199 & & & & & \\
\hline Not protected & & 1881 & 1618 & 746 & 2753 & $56.4 \%[55.2-57.6]$ \\
\hline Protected & & 1410 & 1290 & 555 & 2145 & $43.5 \%$ [42.3-44.7] \\
\hline Time to the Health centre & 5996 & & & & & \\
\hline$<30 \min$ & & 654 & 651 & 244 & 1061 & $21.7 \%[20.7-22.8]$ \\
\hline $30-60 \mathrm{~min}$ & & 903 & 801 & 336 & 1368 & $28.4 \%[27.2-29.5]$ \\
\hline$>60 \mathrm{~min}$ & & 1621 & 1366 & 681 & 2306 & 49. $8 \%[48.5-51.0]$ \\
\hline Food security level & 6189 & & & & & \\
\hline Food security & & 233 & 272 & 77 & 428 & $8.1 \%[7.4-8.8]$ \\
\hline Low food insecurity & & 147 & 149 & 49 & 247 & $4.7 \%[4.2-5.3]$ \\
\hline Moderate food insecurity & & 559 & 617 & 197 & 979 & $19.0 \%$ [18.0-19.9] \\
\hline Severe food insecurity & & 2346 & 1866 & 974 & 3238 & $68.0 \%$ [66.8-69.2] \\
\hline
\end{tabular}

and above. Children who were living at more than one walking hour from the health center had 1.2 (95\% CI: 1.1$1.1 .3 ; p$ : 0.01$)$ times more odds to be stunted and $1.2(95 \%$ CI: $1.1-1.5 ; p: 0.003)$ times more odds to be severely stunted than those living at less than 30 min walking. Children from household experiencing severe food insecurity had 1.4 (95\% CI: $1.2-1.7 ; p<0.001)$ more odds of stunting and 1.6 (95\% CI: 1.3-2.1; $p<0.001)$ more odds of severe stunting than those living in food secured household. Children from poor households were more likely to be stunted compared to all other wealthier categories. Beside these common household level factors associated with stunting and severe stunting, the number of children under five of years in the household was found to be associated with severe stunting (Table 4).

\section{Predictors for stunting}

Male children were more likely to be stunted than girls (AdjOR=1.5; 95\% CI: 1.4-1.8; $p<0.001$ ) (Table 4). Increasing age was associated with stunting (AdjOR $=2.1 ; 95 \%$ CI: $1.8-2.4 ; p<0.001$ for children aged 12-17 months and
AdjOR=3.2; 95\% CI: 2.8-3.7; $p<0.001$ for children aged 18-23 months). Children who were perceived by their mothers to be of medium or smaller size at birth were more likely to be stunted than those who were perceived to be larger (AdjOR=1.5; 95\% CI: $1.3-1.7 ; p<0.001$ ) (AdjOR=2.9; 95\% CI: 2.4-3.6; $p<0.001$ ). Children who were delivered at home were more likely to be stunted (AdjOR $=1.4 ; 95 \%$ CI: 1.2-1.6; $p<0.001$ ) and severely stunted (AdjOR=1.2; 95\% CI: 1.1-1.5; $p=0.03$ ).

Children whose mothers had no schooling were more likely to be stunted compared with children whose mothers attained secondary school or above (AdjOR=1.6; 95\% CI: $1.2-2.1 ; p=0.001)$. Children whose mother uncorrectly assess the nutrition status were more likely to be stunted than those whose mother do (AdjOR $=3.3 ; 95 \% \mathrm{CI}$ : $2.8-4 ; p<0.001)$. Children who were delivered at home were more likely to be stunted (AdjOR=1.4; 95\% CI: 1.21.6; $p<0.001$ ). Being in a household with more than two under five years children was associated with more risk of being stunted than being in a household with one or two under five years children (AdjOR=1.4; 95\% CI: 1.1-1.9; 
Table 4 Factors associated with stunting and severe stunting in Burundian children aged 6-23 months, 2014

\begin{tabular}{|c|c|c|c|c|c|c|c|c|}
\hline \multirow[b]{2}{*}{ Child characteristics } & \multicolumn{4}{|l|}{ Stunted } & \multicolumn{4}{|l|}{ Severely stunted } \\
\hline & Crude OR & $p$-value & Adjusted OR & $p$-value & Crude OR & $p$-value & Adjusted OR & $p$-value \\
\hline \multicolumn{9}{|l|}{ Sex } \\
\hline Female & 1.0 & & 1.0 & & 1.0 & & 1.0 & \\
\hline Male & $1.4[1.3-1.5]$ & $<0.001$ & $1.5[1.4-1.8]$ & $<0.001$ & $1.7[1.5-1.9]$ & $<0.001$ & $1.9[1.6-2.2]$ & $<0.001$ \\
\hline \multicolumn{9}{|l|}{ Age (months) } \\
\hline $6-11$ & 1.0 & & 1.0 & & 1.0 & & 1.0 & \\
\hline $12-17$ & $2.0[1.8-2.3]$ & $<0.001$ & $2.1[1.8-2.4]$ & $<0.001$ & $2.0[1.7-2.4]$ & $<0.001$ & $2.2[1.9-2.6]$ & $<0.001$ \\
\hline $18-23$ & $3.0[2.7-3.4]$ & $<0.001$ & $3.2[2.8-3.7]$ & $<0.001$ & $2.9[2.5-3.4]$ & $<0.001$ & $3.0[2.7-3.9]$ & $<0.001$ \\
\hline \multicolumn{9}{|c|}{ Sickness episode within 2 weeks } \\
\hline No & 1.0 & & & & 1.0 & & & \\
\hline Yes & $1.0[0.9-1.1]$ & 0.31 & & & $1.2[1.1-1.4]$ & 0.003 & & \\
\hline \multicolumn{9}{|l|}{ Place of delivery } \\
\hline Health facility & 1.0 & & 1.0 & & 1.0 & & & \\
\hline Home & $1.4[1.2-1.6]$ & $<0.001$ & $1.4[1.2-1.6]$ & $<0.001$ & $1.3[1.1-1.5]$ & 0.001 & $1.2[1.1-1.5]$ & 0.03 \\
\hline \multicolumn{9}{|c|}{ Exclusive 6 months breastfeeding } \\
\hline No & 1.0 & & & & 1.0 & & & \\
\hline Yes & $1.1[0.9-1.2]$ & 0.20 & & & $0.90[0.77-1.06]$ & 0.20 & & \\
\hline \multicolumn{9}{|c|}{ Continuous to be breastfed } \\
\hline \multicolumn{9}{|l|}{ 6-11 months } \\
\hline No & 1.0 & & & & 1.0 & & & \\
\hline Yes & $1.2[0.2-6.9]$ & 0.27 & & & $0.69[0.08-5.95]$ & 0.74 & & \\
\hline \multicolumn{9}{|l|}{$12-17$ months } \\
\hline No & 1.0 & & & & 1.0 & & & \\
\hline Yes & $1.0[0.7-1.4]$ & 0.11 & & & $0.90[0.57-1.39]$ & 0.63 & & \\
\hline \multicolumn{9}{|l|}{$18-23$ months } \\
\hline No & 1.0 & & & & 1.0 & & & \\
\hline Yes & $0.81[0.62-1.05]$ & 0.12 & & & $0.80[0.62-1.03]$ & 0.09 & & \\
\hline
\end{tabular}

Minimum acceptable diet

\begin{tabular}{|c|c|c|c|c|c|c|c|c|}
\hline \multicolumn{9}{|l|}{ All } \\
\hline No & 1.0 & & & & 1.0 & & & \\
\hline Yes & $1.1[0.9-1.2]$ & 0.25 & & & $0.97[0.84-1.12]$ & 0.68 & & \\
\hline \multicolumn{9}{|c|}{ 6-11 months } \\
\hline No & 1.0 & & & & 1.0 & & & \\
\hline Yes & 1.1 [0.9-1.4] & 0.15 & & & $1.1[0.8-1.6]$ & 0.38 & & \\
\hline \multicolumn{9}{|c|}{ 12-17 months } \\
\hline No & 1.0 & & & & 1.0 & & & \\
\hline Yes & $0.91[0.75-1.11]$ & 0.37 & & & $0.89[0.70-1.12]$ & 0.33 & & \\
\hline \multicolumn{9}{|c|}{ 18-23 months } \\
\hline No & 1.0 & & & & 1.0 & & & \\
\hline Yes & $0.78[0.64-0.96]$ & 0.02 & & & $0.72[0.58-0.91]$ & 0.005 & & \\
\hline \multicolumn{9}{|c|}{ Birth weight proxy (mother's perception of the baby size at birth) } \\
\hline Large & 1.0 & & & & 1.0 & & 1.0 & \\
\hline Medium & $1.5[1.3-1.7]$ & $<0.001$ & $1.5[1.3-1.7]$ & $<0.001$ & $1.5[1.3-1.8]$ & $<0.001$ & $1.6[1.3-1.9]$ & $<0.001$ \\
\hline Small & $2.7[2.2-3.2]$ & $<0.001$ & $2.9[2.4-3.6]$ & $<0.001$ & $3.0[2.4-3.7]$ & $<0.001$ & $3.3[2.6-4.1]$ & $<0.001$ \\
\hline
\end{tabular}


Table 4 Factors associated with stunting and severe stunting in Burundian children aged 6-23 months, 2014 (Continued)

Parental characteristics

Maternal education

Secondary and above

1.0

Primary

No education

Mother's age

$$
\text { 15-24 years }
$$$$
\text { 34-49 years }
$$

Mother's nutrition assessment vs current child's nutrition status

$$
\text { Correct }
$$

Marital status

Live in couple ( married or not) Live alone (div/sep/widow)

Live alone (div/sep/widow)

Household characteristics

Household head education

Secondary and above

Primary

No education

Household Size

$<5$

$$
>=5
$$

\#Children Under 5

$$
1 \text { or } 2
$$$$
>2
$$

\section{0}

3.4 [3.1-3.8]

$<0.001$

1.0

$<0.001 \quad 1.6[1.2-2.1]$

$<0.001 \quad 1.6[1.2-2.1]$

0.002

1.0

$$
2.3[1.7-3]
$$

1.0

$\begin{array}{ll}1.0[0.9-1.1] & 0.91 \\ 1.1[1.0-1.3] & 0.03\end{array}$

1.0

$1.45[1.1-1.9] \quad 0.003$
$1.7[1.1-2.6]$

$2.0[1.3-2.9] \quad<0.001$

1.0

$\begin{array}{ll}1.0[0.9-1.2] & 0.62 \\ 1.1[0.9-1.3] & 0.11\end{array}$

$1.1[0.9-1.3] \quad 0.11$

1.0

$2[1.1-1.14] \quad<0.001$

1.0

$1.5[1.2-1.8] \quad 0.001$

Time to the Health centre

\footnotetext{
$<30$ min

30-60 min

$>60$ min

Arable land ownership

Yes

No
}

Source of drinking water

Protected

unprotected

Food security level

Food secure

Low food insecure

Moderate food insecure

Severe food insecure

SE status

Richest

Richer
1.0

$1.1[0.95-1.4] \quad 0.10$

1.0

$1.7[1.3-2.2] \quad<0.001$

$1.9[1.4-2.4]$

$<0.001$

1.0

$1.0[0.9-1.1]$

0.1

1.0

$1.2[0.97-1.5]$

1.0

$1.1[0.9-1.3] \quad 0.1$

$1.2[1.1-1.3] \quad 0.01$

1.0

$1.0[0.84-1.2] \quad 0.99$

1.0

$1.1[0.96-1.2] \quad 0.23$

1.0

$\begin{array}{ll}1.1[0.8-1.5] & 0.34 \\ 1.0[0.8-1.3] & 0.60 \\ 1.4[1.2-1.7] & <0.001\end{array}$

1.0

$1.4[1.2-1.7]$
1.0

$<0.001$
1.0

$1.7[1.1-2.4] \quad 0.01$

$2.1[1.4-3.0] \quad<0.001$

1.0

$1.0[0.9-1.1] \quad 0.6$

1.0

1.3 [1.1-1.17]

0.03

1.0

$1.5[1.2-1.9] \quad 0.001$

1.0

1.0 [0.8- 1.2] $\quad 0.4$

$1.2[1.1-1.5] \quad 0.003$

1.0

$1.1[0.90-1.3] \quad 0.36$

1.0

$1.0[0.93-1.2] \quad 0.46$

1.0

$\begin{array}{ll}1.1[0.7-1.6] & 0.62 \\ 1.1[0.8-1.4] & 0.44 \\ 1.6[1.3-2.1] & <0.001\end{array}$

1.0

1.0

$\begin{array}{llll}1.4[1.1-1.7] & 0.003 & 1.3[1.1-1.7] & 0.03\end{array}$ 
Table 4 Factors associated with stunting and severe stunting in Burundian children aged 6-23 months, 2014 (Continued)

\begin{tabular}{|c|c|c|c|c|c|c|c|c|}
\hline Middle & $1.7[1.5-2.0]$ & $<0.001$ & $1.5[1.21 .7]$ & 0.001 & $1.8[1.4-2.2]$ & $<0.001$ & $1.6[1.3-2.1]$ & $<0.001$ \\
\hline Poor & 2 [1.6-2.3] & $<0.001$ & $1.7[1.4-2.1]$ & $<0.001$ & $2[1.6-2.5]$ & $<0.001$ & $1.9[1.5-2.4]$ & $<0.001$ \\
\hline Poorest & $2.1[1.8-2.4]$ & $<0.001$ & 2 [1.6-2.3] & $<0.001$ & 2.4 [1.9-2.9] & $<0.001$ & $2.4[1.9-2.9]$ & $<0.001$ \\
\hline
\end{tabular}

$p=0.003)$. Children from poorest households were more likely to be stunted compared to all other categories (AdjOR=2; 95\% CI: 1.6-2.3; $p<0.001$ ) (Table 4).

\section{Predictors for severe stunting}

Age was significantly associated with severe stunting (AdjOR=2.2; 95\% CI: 1.9-2.6; $p<0.001$ for children aged 12-17 months and AdjOR=3.0; 95\% CI: 2.7-3.9; $p<0.001$ for children aged 18-23 months compared to children aged 6 to 11 months) and male children were more likely to be severely stunted than females (AdjOR=1.9; 95\% CI: 1.6-2.2; $p<0.001$ ) (Table 4). Children who were perceived by their mothers to be of medium or smaller size at birth were more likely to be severely stunted than those who were perceived to be larger (AdjOR=1.6; 95\% CI: 1.3-1.9; $p<0.001) \quad(\mathrm{AdjOR}=3.3 ; 95 \% \quad \mathrm{CI}: 2.6-4.1$; $p<0.001)$. Living in a household with more than two under five years children was associated with more odds of being severely stunted than living in a household with one or two under five years children (AdjOR $=1.5$; 95\% CI: $1.2-1.9 ; p=0.001)$. Children from poorest households were more likely to be severely stunted compared to all other categories (AdjOR=2.4; 95\% CI: 1.9-2.9; $p<0.001$ ) (Table 4).

Inappropriate complementary feeding practices was correlated with household socio-economic status $(r=0.1)$ and household food security level $(r=-0.2)$. The latter two were also found to be correlate $(r=-0.3)$.

Collinearity was assessed and found for sanitation and source of drinking water. There was no interaction between independent variables.

\section{Discussion}

The prevalence of stunting and severe stunting among children aged 6 to 23 months was $53.0 \%$ and $21 \%$ respectively. These figures are similar to those from the last DHS conducted in 2010 (58.0\%) [23]. This prevalence is high compared to the estimated prevalence of stunted pre-school children for the UN regions and sub-regions in 2015 [7]. Beside the heavy burden in terms of lost DALYS, international studies have shown that undernutrition is strongly associated with less schooling on the medium term $[4,5]$, and reduced economic productivity on the long term [30], something has to be done in order to stop the vicious circle.

Our study showed that the increased age of the child was associated with stunting and severe stunting. Similar findings were reported in other studies conducted in different LMICs [31, 32]. This could be explained by the inappropriate complementary food that children receive, due to the high prevalence of household's severe food insecurity (68\%). As children are growing up, they need adequate complementary food, in quantity and in quality, as a complement to the breast milk [10, 33]: our study found that only $30 \%$ of the children aged between 18-23 months received appropriate complementary food in regards to both frequency and diversity. In the bivariate analyses, stunting and severe stunting were associated with inappropriate complementary feeding practices but this turned out to be non-significant in the multivariate analysis.

Gender was another predictor of stunting and severe stunting in children aged 6-23 months as boys had higher odds of becoming stunted or severely stunted compared to girls, supporting previous findings in the region [31, 34]. A meta-analysis of 16 demographic and health surveys in Sub-Saharan Africa revealed the same results with an explanation oriented towards a historical pattern of preferential treatment of females due to high value placed on women's agricultural labor [35]. However, such hypothesis cannot be ascertained in our study as there is a gender balance among children who had appropriate complementary food in the previous 24 hours before the survey.

Children whose mothers perceived them to be small or medium size at birth-a proxy of birth weight- were found to be at higher odds of being stunted and severely stunted compared to those perceived to be larger. Other studies conducted in Tanzania in 2015 and in Nepal in 2014 had the same findings $[31,36]$. More recently, a cohort study conducted in Benin confirms that low birth weight was associated with growth impairment [37].

Our study also reveals that mothers assessing correctly the child nutrition status were less likely to have stunted children than those who did not assess this correctly. This could let assume that mothers who reserved time to learn how to evaluate child nutrition status are the ones who invest in the latter.

Children whose mothers reached secondary school and above were less likely to be stunted than those whose mothers had no schooling which also have been shown in previous studies elsewhere [33]. These two findings demonstrate the importance of education of girls as one strategy to overcome the burden of stunting and to promote good feeding practices for young children. In the present study, children who were delivered at health facility were 
less likely to be stunted compared to those delivered at home. This matches with findings from the Tanzanian (2015) and Kenyan (2012) studies [31, 34]. This finding hypotheses that mothers who delivered at health facility often use health services, and are thus more informed about good child health care practices.

Children belonging to households with more than two under five children were more likely to be stunted or severely stunted than the others. These results are similar to those found in Somalia [38]. Indeed, more under five children in the family may lead to a higher risk of having insufficient complementary food in a context of severe food insecurity. The children from the poorest socio-economic class were more likely to be stunted and severely stunted than all other categories. This finding is also supported by different studies conducted in LMIC $[32,39]$.

The factors that our study revealed to be predictors for stunting and severe stunting can be classified according the WHO conceptual framework on childhood stunting 12] into household and family factors (maternal factors and home environment) such as: maternal education, mother's nutrition status assessment, number of under five years children in the household, size at birth. The others are found to be predictors that are reflected in the context in which the child lives: socio-economic status, place of delivery. As mentioned above, these findings are supported by other studies done elsewhere.

\section{Strengths and weaknesses of the study}

The big size of our sample makes our findings precise and reliable for the whole population of the rural parts of Burundi. Though we cannot extrapolate the findings to other countries, they however suggest some trends in similar settings. However since the study has been conducted in rural areas, our findings are not applicable as such for urban settings.

We considered many more variables than previous studies, such as mother's knowledge on child's nutrition status assessment, household's food security, birth weight proxy, place of delivery, arable land ownership.

A weakness from the surveys was that any reading note wasn't submitted to the interviewee to make sure of his ability to read and write: this didn't allow us to consider the literacy variable for the analysis. Another weakness is that we didn't push further to investigate community and societal factors specifically political economy factors and health factors of the WHO conceptual framework on childhood stunting.

\section{Implications for future research}

The study suggests possible new paths for action which could trigger different action research projects, through nutrition community interventions, sensitization for family planning, young girls education, etc. As for the impact of performance-based financing as a mean to reduce malnutrition, through e.g. support nutrition community interventions, we will wait for the follow-up household survey (due early 2017) to perform the impact analyses. Possible other paths for action to study would be better targeting (e.g. through a demand-side financing scheme focused on poorest households), and nutrition community interventions (e.g. sensitization).

\section{Conclusion}

We observed that child's age, boys, a small birth weight (as perceived by the mother), more than two children under-five years of age in the household and household's poor socioeconomic status were factors associated with stunting and severe stunting. Modeling selected that, mother's education level, mother's knowledge about child nutrition status assessment and health facility delivery were predictors of child stunting.

Our study confirms that stunting and severe stunting is in Burundi, as elsewhere, a multi-sectoral problem. Some determinants relate to the general development of Burundi: education of girls, poverty, and food security; will be addressed by a large array of actions. Some others relate to the health sector and its performance we think in particular of the number of children under five in the household (birth spacing), the relationship with the health center and the knowledge of the mother on malnutrition. Our findings confirm that the Ministry of Health and its partners should strive for better performing and holistic nutrition services: they can contribute to better nutrition outcomes.

\section{Endnotes}

${ }^{1}$ Twice a week, external supervisors followed randomly chosen surveyors and measured again the weight, height, MUAC and oedema presence among the surveyed children; their measurements were confronted to the ones performed by the surveyors and errors were discussed with them. Observed discrepancies were null on average and big discrepancies (more than 200g for weight and $5 \mathrm{~mm}$ for height and MUAC) were rare which tend to confirm that anthropometrics were of good quality.

\section{Abbreviations \\ AdjOR: Adjusted Odds Ratio; cOR: Crude Odds Ratio; DHS: Demographic and Health Survey; FANTA: Food and Nutrition Technical Assistance; GDP: Gross Domestic Product; HFIAS: Household Food Insecurity Access Scale; \\ IRB: Institutional Review Board; LMIC: Low and Middle Income Country; NCT: National Clinical Trial; PBF: Performance Based-Financing; SD: Standard Deviation; SDG: Sustainable Development Goals; UNICEF: United Nations of International Children's Emergency Fund; WHO: World Health Organization.}

\section{Acknowledgements}

We would like to extend our deepest gratitude to the World Bank for financing the Impact Evaluation of Introduction of Nutrition criteria in the PBF program in Burundi. Our appreciation goes to Pr Patrick Kolsteren and 
Dominique Roberfroid for their valuable contributions during the early design of the intervention. The authors would like to thank the persons from the Nutrition Program in Burundi, Kirrily de Polnay, Ulises Huerta, Elodie Macouillard, Manassé Nimpagaritse and Léonard Ntakarutimana for their support in the preparation and implementation of the baseline surveys. The authors would also like to thank the ISTEEBU team who realized the baseline survey. Our appreciation goes to the data collectors and supervisors. Lastly, our special thanks also go to mothers who participated in the study.

\section{Funding}

The research project (PBF-Nutrition in Burundi) is funded by the World Bank and the field work of the corresponding author (quality assurance during data collection, qualitative data collection, analysis, interpretation and writing) is funded by VLIR-UOS.

\section{Availability of data and materials}

The datasets used and/or analyzed during the current study available from the corresponding author on reasonable request.

\section{Authors' contributions}

$\mathrm{SN}$ involved from acquisition of data, analysis and interpretation and wrote the paper. CK involved in the inception to design the study, analysis and interpretation and revised the manuscript. BM involved in the inception to design the study and revised the manuscript. JPVG involved in the data analysis and interpretation, revised the manuscript for the final submission. All authors read and approved the final manuscript.

\section{Ethics approval and consent to participate}

We used data from a household baseline survey of an Impact Evaluation study of the performance-based financing scheme applied to nutrition services in Burundi at health center level and community level. The ethical clearance was obtained from the Institutional Review Board (IRB) in Belgium and the Burundian Ethics Committee. Informed consent was signed by the respondent and all information was collected confidentially.

\section{Consent for publication}

Not applicable.

\section{Competing interests}

The authors declare that they have no competing interests.

\section{Publisher's Note}

Springer Nature remains neutral with regard to jurisdictional claims in published maps and institutional affiliations.

\section{Author details}

${ }^{1}$ Global Health Institute, University of Antwerp, Gouverneur Kinsbergencentrum, Doornstraat 331-, -2610 Wilrijk, BE, Belgium. ${ }^{2}$ Health Community Department, University of Burundi, Boulevard du 28 NovembreBP 1020 Bujumbura, Burundi. ${ }^{3}$ Health Economics Unit, Department of Public Health, Institute of Tropical Medicine, Nationalestraat 155, 2000 Antwerp, Belgium

Received: 7 December 2016 Accepted: 20 July 2017 Published online: 25 July 2017

\section{References}

1. United Nations. Sustainable Development Goals. http://www.un.org/ sustainabledevelopment/hunger/. 2016. New York, United Nations. 5-5-2016.

2. Black RE, Allen LH, Bhutta ZA, Caulfield LE, de Onis M, Ezzati M, et al. Maternal and child undernutrition: global and regional exposures and health consequences. Lancet. 2008;371(9608):243-60.

3. UNICEF, WHO, WB. Levels and Trends in Child malnutrition. New York: UNICEF; 2015

4. Grantham-McGregor S, Cheung YB, Cueto S, Glewwe P, Richter L, Strupp B. Developmental potential in the first 5 years for children in developing countries. Lancet. 2007:369(9555):60-70.

5. Victora CG, Adair L, Fall C, Hallal PC, Martorell R, Richter L, et al. Maternal and child undernutrition: consequences for adult health and human capital. Lancet. 2008;371(9609):340-57.
6. WHO. Children: reducing mortality. http://www.who.int/mediacentre/ factsheets/fs178/en/. 2016. Geneva, WHO. 5-5-2016.

7. de Onis M, Blossner M, Borghi E. Prevalence and trends of stunting among pre-school children, 1990-2020. Public Health Nutr. 2012;15(1):142-8.

8. Petrou S, Kupek E. Poverty and childhood undernutrition in developing countries: a multi-national cohort study. Soc Sci Med. 2010;71(7):1366-73.

9. Black RE, Victora CG, Walker SP, Bhutta ZA, Christian P, de Onis M, et al. Maternal and child undernutrition and overweight in low-income and middle-income countries. Lancet. 2013;382(9890):427-51.

10. Dewey KG, Mayers DR. Early child growth: how do nutrition and infection interact? Matern Child Nutr. 2011;7(Suppl 3):129-42.

11. UNICEF. Tracking progress on child and maternal nutrition: a survival and development priority. New York: UNICEF; 2009.

12. Stewart $C P$, lannotti L, Dewey KG, Michaelsen KF, Onyango AW Contextualising complementary feeding in a broader framework for stunting prevention. Matern Child Nutr. 2013;9(Suppl 2):27-45.

13. World Bank. Country overview. 2015. 22-11-2016.

14. UNICEF. Improving Child Nutrition. New York: UNICEF; 2013.

15. Banque Mondiale. Taux de Mortalité Infantile. http://donnees.banquemondiale. org/indicateur/SH.DYN.MORT. 2016. Washington,DC, BM. 5-5-2016.

16. Ouedraogo I, Muhire F. Enquête Nutritionnelle des enfants de 6 à 59 mois des communes de Cendajuru, Kinyinya et Gisuru. Bujumbura: Croix Rouge Belgique; 2014

17. Parker M, Leroy JL, Olney D, Harris J, Ruel M. Strengthening and Evaluating the Preventing Malnutrition Malnutrition in Children under two Approach (PM2A) in Burundi: Baseline report. Washington,DC: FHI360/FANTA; 2012

18. Olney D, Parker ME, Iruhiriye E, Leroy J, Ruel M. A Process Evaluation of the Tubaramure Program for Preventing Malnutrition in children under 2 Approach (PM2A) in Burundi. Washington,DC: FHI360/FANTA; 2013.

19. Leroy J, Heckert J, Cunningham K, Olney D. Strengthening and Evaluating the Preventing Malnutrition in Children under 2 Years of Age Approach. Washington, DC: FHI 360/FANTA; 2014.

20. UNICEF. Analyse de la malnutrition des enfants au Burundi. Bujumbura: UNICEF; 2013

21. Bundervoet T, Verwimp P, Akresh R. Health and Civil War in Rural Burundi. Germany: Institute for the Study of Labor; 2007.

22. Nimpagaritse $M$, Korachais $C$, Roberfroid D, Kolsteren $P$, Zine Eddine El Idrissi $M D$, Meessen B. Measuring and understanding the effects of a performance based financing scheme applied to nutrition services in Burundi-a mixed method impact evaluation design. Int J Equity Health. 2016;15(1):93.

23. Institut de Statistiques et d'Études Économiques du Burundi (ISTEEBU), Ministère de la Santé Publique et de la Luttecontre le Sida [Burundi] (MSPLS), ICF International. Enquête Démographique et de Santé 2010. Bujumbura: ISTEEBU, MSPLS, ICF International; 2012.

24. Carl Hartung YAWBALCTGB. Open Data Kit: Tools to Build Information Services for Developing Regions. London: ICTD; 2010

25. WHO. WHO Child Growth Standards. Geneva: WHO; 2006.

26. Channon AA. Can mothers judge the size of their newborn? Assessing the determinants of a mother's perception of a baby's size at birth. J Biosoc Sci. 2011:43(5):555-73.

27. WHO, UNICEF, IFPRI, FANTA2, USAID, UCDAVIS, et al. Indicators for assessing infant and young feeding practices. Geneva: WHO; 2011.

28. Coates J, Swindale A, Bilinsky P. Echelle de l'Accès déterminant I'Insécurité alimentaire des Ménages (HFIAS) pour la Mesure de l'Accès Alimentaire des Ménages: Guide d'Indicateurs. Washington, DC: FANTA; 2007

29. Vyas S, Kumaranayake L. Constructing socio-economic status indices: how to use principal components analysis. Health Policy Plan. 2006; 21(6):459-68.

30. Hoddinott J, Maluccio JA, Behrman JR, Flores R, Martorell R. Effect of a nutrition intervention during early childhood on economic productivity in Guatemalan adults. Lancet. 2008:371(9610):411-6.

31. Chirande L, Charwe D, Mbwana H, Victor R, Kimboka S, Issaka Al, et al. Determinants of stunting and severe stunting among under-fives in Tanzania: evidence from the 2010 cross-sectional household survey. BMC Pediatr. 2015;15:165.

32. Ramli AKE, Inder KJ, Bowe SJ, Jacobs J, Dibley MJ. Prevalence and risk factors for stunting and severe stunting among under-fives in North Maluku province of Indonesia. BMC Pediatr. 2009;9:64.

33. Prendergast AJ, Humphrey $\mathrm{JH}$. The stunting syndrome in developing countries. Paediatr Int Child Health. 2014;34(4):250-65. 
34. Abuya BA, Ciera J, Kimani-Murage E. Effect of mother's education on child's nutritional status in the slums of Nairobi. BMC Pediatr. 2012;12:80.

35. Wamani H, Astrom AN, Peterson S, Tumwine JK, Tylleskar T. Boys are more stunted than girls in sub-Saharan Africa: a meta-analysis of 16 demographic and health surveys. BMC Pediatr. 2007;7:17.

36. Tiwari R, Ausman LM, Agho KE. Determinants of stunting and severe stunting among under-fives: evidence from the 2011 Nepal Demographic and Health Survey. BMC Pediatr. 2014;14:239

37. Padonou G, Le PA, Cottrell G, Guerra J, Choudat I, Rachas A, et al. Factors associated with growth patterns from birth to 18 months in a Beninese cohort of children. Acta Trop. 2014 Jul;135:1-9.

38. Kinyoki DK, Kandala NB, Manda SO, Krainski ET, Fuglstad GA, Moloney GM, et al. Assessing comorbidity and correlates of wasting and stunting among children in Somalia using cross-sectional household surveys: 2007 to 2010. Bmj Open. 2016:6(3):e009854

39. Black RE, Victora CG, Walker SP, Bhutta ZA, Christian P. de OM, et al. Maternal and child undernutrition and overweight in low-income and middle-income countries. Lancet. 2013;382(9890):427-51.

Submit your next manuscript to BioMed Central and we will help you at every step:

- We accept pre-submission inquiries

- Our selector tool helps you to find the most relevant journal

- We provide round the clock customer support

- Convenient online submission

- Thorough peer review

- Inclusion in PubMed and all major indexing services

- Maximum visibility for your research

Submit your manuscript at www.biomedcentral.com/submit
Biomed Central 